\title{
Technological Innovation for Online Learning during the Situation of COVID-19 Pandemic in Thailand
}

\author{
Phraratsutaporn ${ }^{1}$, Lampong Klomkul ${ }^{2}$ \\ ${ }^{1,2}$ Faculty of Education, Mahachulalongkornrajavidyalaya University, Thailand \\ Email: ${ }^{1}$ phraratsutaporn@gmail.com, ${ }^{2}$ research.mcu@gmail.com
}

\begin{abstract}
Online learning in Thailand during the situation of COVID-19 pandemic is appropriate for current educational management. This learning method has been shown good prevention of COVID-19 pandemic, and it was being a measure to control the situation effectively. The purpose of this academic paper was to propose technological innovation for online learning during the situation of COVID-19 pandemic. Documentary study was used for data collection and data were analyzed and presented by descriptive writing. Results of the study indicated that educational technology has played important role for teaching and instruction during COVID-19 pandemic. Active learning and collaborative activities have been using for the learners to have the opportunity to study from home during the situation of COVID-19 pandemic. Various technological platforms were used for online learning consisted of Google meet, Google Classroom, Google Hangout Meet, Live Streaming, Tencent Live Broadcast, Microsoft teams, and Zoom. These teaching instruments are required and all educational personnel should be able to use with effectively in order to encourage their learners on teaching and instruction. Therefore, technological innovations for online learning are developed for teaching and learning in New Normal not only in Thailand, but also all over the world. Blended learning was also being used and teachers need to adjust how to manage their classroom in online platform and how to moderate or mentor with online learning during the situation of COVID-19 pandemic.
\end{abstract}

Keywords

Inexperienced Parents, Stability Reinforcement, Buddhism

Article Received: 10 August 2020, Revised: 25 October 2020, Accepted: 18 November 2020

\section{Introduction}

The concept of technological innovation for learning has been of constant importance to the global society ever since we have heard the term "The Third Wave", according to Alvin Topler, mentioned the term "Globalization" is the rapid influx of information from one corner of the world to another, and the term turbulent world (Disruption) is a rapid change in technology flows innovation and social media. When it comes across a strong and fast catalyst, the COVID19 epidemic, the global society is subjected to automatic change under the term New normal, transforming humanity of learning history in the wake of the terrible COVID-19 epidemic. Online learning has become a necessity or a new way of learning in current global society. Whether voluntary or not, online learning is therefore a new paradigm in teaching and learning in the New Normal era.

It will first mention the importance of "online" as an innovative technology for learning. It will give an overview or a broad picture of the technological innovation for learning to be the first floor covering first. In formulating Thailand's national education policy, the educational policy supervisor established the national education standard in 2018 by determining the desirable outcomes of education (DOE Thailand) or the characteristics of the Thai 4.0 people responding to the world that change in the future and the vision of national development towards stability, prosperity, and sustainability. It is a person with three characteristics consisted of being a learner, innovation co-creator, and a strong citizen focusing on the main principles in practice. The provision of education is appropriate to the context of the learner, community area and society, including the freedom of the educational institution to determine the identity and directions for education management that meet the needs of learners of the local community (Office of the Education Council Secretariat, 2018) [1].

Wirathai Santipraphob (2019)mentioned that "Thai people" preparation for the modern world that Thai people can cope with changes in the modern world at least four skills are required: 1) lifelong learning skills, 2) financial planning skills, 3) social coexistence skills, and 4) good mental immunity. The urgent burden of Thai society for human resource development is stressed, and that is to improve various motives correct human development throughout life along with the application of technology and innovation to enable Thais to develop and elevate themselves to the context of the modern world quickly and efficiently (Wirathai Santipraphob, 2019: 10-21) [2].

From the article of Numporn Nithisunthornwit (1990) on the title of "Science Development Technology and innovation to enhance Thailand's competitiveness " mentioned support for enhancing economic competitiveness and laying the foundation for sustainable development. They should focus on the application of existing technology. The development of local wisdom Developing innovations that meet the needs of the manufacturing sector Strengthening the foundation of scientific thinking for youth and Thai society and continuously develop science and technology personnel to enhance the development that leads to the economy and society, sustainable learning by approaches such as 1) development and application and development of technologies that are important to increase productivity by supporting research and development according to the potential of entrepreneurs, both large and small and SMEs, adopt modern technology to be adapted to meet local wisdom and the manufacturing sector appropriately and in 
line with market needs. Along with supporting the private sector to be a leader in research and development including technology and innovation for commercial use with a focus on the field of manufacturing that Thailand has potential. Interesting issues of this paper in the area of capacity building in health and welfare, it is to improve the quality of life of Thai people by promoting research and development in biotechnology, medical and public health to monitor and prevent heal and restore including research and development of chemicals, bio-products and equipment as well as to produce main drugs in the country to treat common diseases to meet the needs of all circumstances. 2) To initiate innovative development by supporting the introduction of new technologies, concepts and management to develop innovation in industrial processing from agricultural raw materials food industry and equipment for maintaining environmental conditions promote the use of machinery and tools of Thai people especially agricultural machinery. It is including improving agricultural machinery to have quality standards to reduce machinery imports and reduce production costs. 3) Reform the education system and develop learning processes to strengthen the concept and knowledge about the use of science and technology to keep up with the changes and modern science focus on students to think, analyze and solve problems systematically, logically as a science and take action by yourself and providing opportunities for the community and the private sector to participate in curriculum development and teaching and learning evaluation (Numporn Nithisunthornwit, 2013: 37-44) [3].

\section{Online Teaching and Learning Management Online Teaching and Learning in Wuhan at the Start of COVID-19 Outbreak}

When the disease is infected with COVID-19 Epidemic started in Wuhan, China, the Chinese authorities announced a ban on people traveling, including the closure of classes from January 13, 2010 until February 10, 2020. The Wuhan Department of Education announced the closure of classes but did not stop teaching by announcing a ban on teachers, students and government personnel to meet together to prepare for teaching and learning as well as allowing educational institutions to open online teaching and learning at the same time for all levels of education. On the official opening day of the semester require all students to sing the national anthem in unison online, in front of a computer monitor, laptop, mobile phone. The school has chosen a student representative to be an online. The school director welcomed the students and gave a sermon. Most of the themes address the social malfunctions caused by the COVID-19 epidemic, let students understand the difficult situation of the country by asking students to have love empathize, unite, let everyone do their duty and be responsible for society, country and world society. As well as encouraging that Wuhan will be able to overcome this disaster and students will soon return to their school same as instructing students to attend online classes in accordance with the schedule provided since there is still checking the name of the participants like studying in a school classroom.

This is because China had not previously prepared to offer such a broad range of online teaching and learning.
The government has spent a certain amount of budget to implement this matter and private grandchildren have been involved in the design of the Application (App) in a variety of formats. So that the education department can use them to suit the conditions in each area and each subject. For preparing teachers, faculty, educational personnel, and the government has created a program for educating teachers and faculty members to be competent in online tutoring on the website. www.eduyun.cn, a national public service platform for educational resources that guides teachers and faculty with instructional procedures and methods to teach online by preparing staff to answer questions when teachers and faculty have problems. Teachers in different schools can use App with free of charge. In addition, the Wuhan Department of Education has ordered teachers and faculty to jointly create (Online coordination) courses, teaching materials carry out planning, prepare instruction manual and lifestyle plan for students with an emphasis on maintaining the mental state of students. They also establish a system for reporting students outside the school and schedule a time to communicate with students to get an idea of each student's online learning situation either by telephone or any other form of online communication. There is an emphasis on the care of individual students in which the homeroom teacher or the subject must act as a guide and be a mentor in the teaching hours. Some subjects may have outstanding national teachers as teachers in the App provided by the Department of Education where teachers and students will learn together.

Parents are also one of those affected by this online teaching. For teaching preschool and elementary school students, parents need to provide their children with online tools with at least a cell phone. It may be necessary to help a young child download the textbooks, learning materials before the online study hours. Most of the students are excited about this innovative way of learning. Even at first there was a problem for some students who still did not download the document completely. Due to the large number of users, there is some involvement. The Wuhan Department of Education conducted an evaluation of the results of the tuition in the two weeks following the opening of the online semester. It can be summarized as follows advantages students have the opportunity to study with some of the country's best teachers and faculty members. It is because the class teacher or the subject can download the App for outstanding teachers or teachers of the country to teach. It is a great opportunity for students. It is one way to distribute the equality of learning opportunities. While the teachers had the opportunity to learn good quality teachers teaching methods, parents can download information, documents, texts, App with good quality and given to children without cost.

\section{Obstacles that are a challenge to improve and improve}

1) Internet signal in some places is not strong enough for large usage. 2) Teachers, students and parents lacked online learning experience. It made me feel that the teaching was not as convenient as studying in the classroom that can communicate in two ways and see each other clearly in every angle. 
2) Hours of online study through mobile phones, notebooks, computers all day causing pupils to have visual problems and after-hours students lose concentration.

3) Students who are slow to learn according to online teaching because when the teacher explained it passed, it was passed. Students have to wait until the end of the hour, then the teacher will have time to ask questions or exchange ideas for half an hour. If students sometime in doubt of the content, they are unable to understand the next step [4].

\section{Online Instruction in the USA}

Online learning in USA has been using for along time as Kyong-Jee Kim and Curtis J. Bonk (2006) [5] mentioned in "The Future of Online Teaching and Learning in Higher Education" that a recent survey of higher education in the United States reported that more than 2.35 million students enrolled in online courses in fall 2004. This report also noted that online education is becoming an important longterm strategy for many postsecondary institutions. Given the rapid growth of online education and its importance for postsecondary institutions, it is imperative that institutions of higher education provide quality online programs. The literature addresses student achievement and satisfaction as two means to assess the quality of online education. Studies focused on academic achievement have shown mixed reviews, but some researchers point out that online education can be at least as effective as traditional classroom instruction. Several research studies on student satisfaction in online courses or programs reported both satisfied and dissatisfied students. Faculty training and support is another critical component of quality online education. Many researchers posit that instructors play a different role from that of traditional classroom instructors when they teach online courses as well as when they teach residential courses with web enhancements. Such new roles for online instructors require training and support. Some case studies of faculty development programs indicate that such programs can have positive impacts on instructor transitions from teaching in a face-to-face to an online setting.

As institutions of higher education continue to embrace and debate online learning, it is important to envision where the field is headed. What might the next generation of online learning environments look like? Will they move from warehousing students in online environments to engaging them in and motivational activities? What technological and pedagogical advantages will they offer? Current studies provide a glimpse of the pedagogical and technological possibilities. Clearly, we are entering a unique and exciting era in online teaching and learning. And perhaps the perfect e-storm is becoming less cloudy and ominous.

For implications of the findings, institutions of higher education need to consider whether they are ready to meet growing learner demands in the coming years. First of all, most respondents agreed that blended learning would have greater significance in higher education in the future. Although some institutions have already embraced blended learning, many others are slower at adopting it for various reasons. Perhaps leadership from the institution is crucial for faculty to receive adequate support to implement changes in the teaching process.
If the quality of online education is to improve as projected from this study, campuses must also look at the pedagogical issues in online learning. Collaboration, case learning, and PBL are likely to be the preferred methods of online instructors, with few relying solely on traditional methods. The data presented here also indicate that the continued explosion in online learning will bring increased attention to workshops, courses, and degree programs in how to moderate or mentor with online learning, and given that many respondents expect to receive some sort of training and support from their institutions to be ready for online teaching, colleges and universities need to consider how they will respond to these needs.

In addition, our study indicates that postsecondary institutions are finally focusing on how online learning can develop student collaboration and evaluation skills. In fact, most now see the potential of the web in the coming years as a tool for virtual teaming or collaboration, critical thinking, and enhanced student engagement, though not necessarily as a tool for creative and individual expression. Do current CMSs provide tools to realize the potentials of the Web for innovative teaching and learning? Perhaps recent developments in open source courseware will force CMS vendors to develop and market more pedagogically engaging tools and resources.

This survey also forecasts enormous growth in online certification and recertification programs, as well as some growth in associate's and master's degree programs during the coming decade. In terms of technology, the study reveals interest among online instructors in wireless technologies, simulations, digital libraries, and reusable content objects. We perhaps are entering a world where learning objects will be at our fingertips. Learning objects on different topics will likely be something you can grab like magazines and newspapers on the way into a plane, bus, or train. In addition, as bandwidth increases with the next-generation internet technologies and capabilities, simulation and gaming tasks that online students engage in will be more realistic and authentic (Kyong-Jee Kim and Curtis J. Bonk, 2006: 22-29) [6].

Elaine Allen and Jeff Seaman (2010) [7] mentioned that Learning on Demand: Online Education in the United States, 2009 (Learning on Demand: Online Education in the United States, 2009) represents the seventh annual report on the state of online learning among higher education institutions in the United States. The study is aimed at answering some of the fundamental questions about the nature and extent of online education based on responses from over 2,500 colleges and universities, the report addresses the following key questions: (1) How Many Students are Learning Online?; (2) What is the Impact of the Economy on Online Education?; (3) What Contingency Plans do Institutions Have for H1N1?; (4) Is Online Learning Strategic?; (5) Has Faculty Acceptance of Online Increased?; and (6) Do Faculty Receiving Training for Teaching Online? The survey analysis is based on a comprehensive sample of active, degree-granting institutions of higher education in the United States that are open to the public. Findings reveal that online enrollments have continued to grow at rates far in excess of the total higher education student population, with the most recent data demonstrating no signs of slowing. Academic leaders at 
all types of institutions report increased demand for face-toface and online courses, with those at public institutions seeing the largest impact. In all cases the demand for online offerings is greater than that for the corresponding face-toface offerings. Proponents of online learning have long posited that moving face-to-face classes online could become an important component of academic continuity planning. A potential H1N1 pandemic is such an event that might trigger such planning. This year's results show a very small increase from the previous year and begin to signal that a plateau may have been reached by institutions believing that online is critical to their long-term strategy. While the number of programs and courses online continue to grow, the acceptance of this learning modality by faculty has been relatively constant since first measured in 2002 . There is no single approach being taken by institutions in providing training for their teaching faculty. Most institutions use a combination of mentoring and training options. Additional tables are appended. [For the previous report, "Staying the Course: Online Education in the United States, 2008."

This idea will lead to the introduction of innovative technologies for online learning during the COVID-19 epidemic. The more concrete issue will be discussed further.

\section{Online Learning}

From the article of Aaron Doering (2007) [8] indicated that "Adventure Learning: Transformative hybrid online education" mentioned that Adventure Learning (AL) is a hybrid distance education approach that provides students with opportunities to explore real-world issues through authentic learning experiences within collaborative learning environments. This article defines this online distance education approach, outlines an AL framework, and showcases an AL archetype. In AL environments, classroom teachers are not positioned in the role of teacher/facilitator/designer in the online learning spaces. AL online spaces are collaborative spaces where students, teachers, subject experts, and AL team members interact with one another; these are community spaces where traditional hierarchical classroom roles are blurred. Student' roles transform due to the flexibility and design of the $\mathrm{AL}$ learning environments as they move from student to reflective practitioner, providing for new ways of learning and teaching.

In the research of Sean B. Eom, H. Joseph Wen and Nicholas Ashill (2006) [9] on "The Determinants of Students' Perceived Learning Outcomes and Satisfaction in University Online Education: An Empirical Investigation" In this study, structural equation modeling is applied to examine the determinants of students' satisfaction and their perceived learning outcomes in the context of university online courses. Independent variables included in the study are course structure, instructor feedback, self-motivation, learning style, interaction, and instructor facilitation as potential determinants of online learning. A total of 397 valid unduplicated responses from students who have completed at least one online course at a university in the Midwest were used to examine the structural model. The results indicated that all of the antecedent variables significantly affect students' satisfaction of the six antecedent variables hypothesized to affect the perceived learning outcomes, only instructor feed-back and learning style are significant. The structural model results also reveal that user satisfaction is a significant predictor of learning outcomes. The findings suggested that online education can be a superior mode of instruction if it is targeted to learners with specific learning styles (visual and read/write learning styles) and with timely, meaningful instructor feedback of various types.

\section{Technological Innovations for Online Learning during the COVID-19 Epidemic}

As COVID-19 accelerates education systems around the world, more educational technology is used, as Jeanne Allen, founder and CEO of the Center for Education Reform, analyzed in Forbes (WORATHAN TECHNOLOGY, 2020) [10] that there was a saying that: every challenge times as with many educational systems in the past, many educational systems have long resisted structural changes. As a result of the development of the Coronavirus, or COVID-19 pandemic, education sector is imperative to find a way for the education system to continue with effectively.

The use of educational technology or educational technology used in teaching and learning help to make the presentation of teaching and learning content more interesting and build engagement between students and more teachers. Even when everyone has to live within their accommodation during COVID-19 situations, this ensures that students will not miss their learning and help students learning path, and can move on for example New Jersey began considering legislation that educational institutions can use "Virtual Education" technology in their teaching and learning. When an emergency occurs, such as the outbreak of the COVID-19 virus, but Jeanne Allen asks whether so why use technology and education only in an emergency? Because in the creation of new educational standards, the world of Educational Technology or "EdTech" allows faster, smarter and more efficient teaching and learning styles. Personalization for example, the Northshore School District case study, which has 33 schools, has designed teaching and learning to be cloud based and used online as a teaching tool to build 21 st century skills for student's digital skills, critical thinking, problem solving, collaboration, creativity which learning through the cloud system allows students to learn continuously and leave the framework of learning that is limited to the rectangular classroom. There is an application about education and has AR, VR and AI technologies to meet the needs of education for learners. We don't need a crisis and to rethink the education system, but technology can change the role of teachers from being a guide into sponsorship and give advice to learners. It is hoped that the COVID-19 situation will mirror that innovation and technology can help students. Students and educational institutions go through this time and will continue to see the use of innovation and education technology is typical of the education system using "Tech Company" technology platform to create "online classrooms", where you can learn, one of the most obvious phenomena in the COVID-19 situation is that Tech Company's technology platform is applied to online teaching and learning. Nowadays, people 
access the internet and communication technology developed in $4 \mathrm{G}$ and some countries have reached $5 \mathrm{G}$, making online teaching more convenient and faster, such as

1) DingTalk communication platform and working in the organization, another Alibaba-affiliated service has been applied to online teaching and learning systems in China. During the COVID-19 crisis, more than 50 million students. Students participated in the online classroom program. It is open to more than 600,000 teachers teaching various subjects via Live Streaming.

2) Tencent uses Tencent Live Broadcast to meet online education needs in China during the COVID-19 epidemic, such as in Wuhan. The data on February 10, the past found that on Tencent's Live Streaming system, there are elementary school students and junior high school in Wuhan, up to 81 percent or more than 730,000 people of the number of primary school students and junior high school in Wuhan, all more than 900,000 people learn online via Tencent Live Streaming.

3) Google Hangout Meet which an online meeting technology supporting multiple people meetings as well as being able to live streaming to support a large audience and save the meeting on Google Drive.

It appears that during COVID-19, schools and universities turn to use these two Google products to make teaching and learning easier outside the classroom (Marketingoops, 2020) [11]. These tools are essential to provide the teaching and learning that teachers and educational personnel must learn how to apply technological innovations for online learning during the COVID-19 epidemic in order to be effective in teaching and learning in this New Normal era.
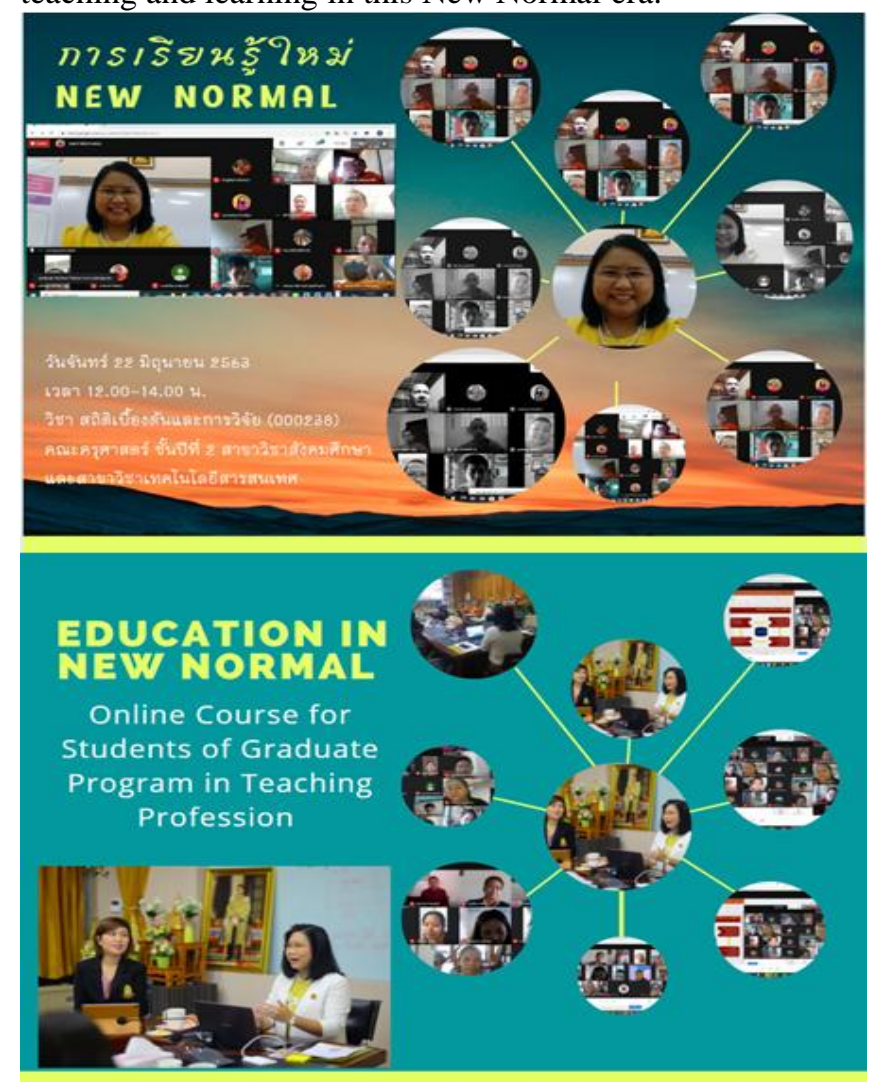

Fig.1 The New Normal way in which education is not in class, school, university, but everywhere, anytime under the goal of learning to learn remains the same, but the method has changed.

\section{Technology And Innovation To Support Teaching And Learning Among Covid-19}

Online teaching has interesting technologies and innovations as follows:

\section{LMS2@PSU (LMS Model)}

The LMS @ PSU system was established for the purpose of supporting the teaching and learning of teachers and students within Prince of Songkla University. The system itself is based on a free software called Moodle (Modular Object-Oriented Dynamic Learning Environment), which allows users to create online lessons in the system to apply them to teaching in the form. The way the teacher wants the highlight is that it is an existing university learning management system. There are tools to assist in student management. There are tools to assist in the preparation of content and links such as Word, Power Point, Youtube, communication tools such as Chat, Webboard, Zoom Plugin, learning measurement and evaluation tools such as Quiz, Poll, Survey, and support for theory. The disadvantage is that it is difficult to use and complex tools.

\section{Microsoft Teams}

Microsoft Teams is a Microsoft service that is a hub for teamwork in Office 365 with full functionality, such as inviting everyone you work with to chat, meet, call, and collaborate on the single place. It is no matter where the user is for schools, Microsoft Teams will be in Office 365 Education, a customized hub for managing classes such as school material. Student notebook assignment creation of exercises, tests, grading, online teaching, etc. The highlight is that it is an existing university learning management system, and can be used with all communication tools such as PC, Notebook, Tablet, Ipad, Smart Phone. It also can be used with all operating systems Windows, macOS, iOS, Android. There is a student management tool. There are tools to help you prepare content and links and have communication tools. There are tools to measure and evaluate grades, have AI and bot systems such as anti-piracy systems, making a quiz, and creating a survey.

\section{Google Classroom}

Google Classroom, a Google service, is a tool that facilitates education, designed to give teachers more time to communicate with learners, while at the same time they have more time to search for information. As well Key Google Classroom capabilities include: Create and store study data using Google Docs, Drive, and Gmail.Teachers can review their studies at all times and provide guidance to students at any time. Increase communication channels between teachers and learners. This allows them to provide guidance to students at all times, even when they are not in the classroom. Each student's information folder can be categorized, and each student can easily use the information. The highlight is the existing university learning management system. Can be used with all communication tools such as PC, Notebook, Tablet, Ipad, Smart Phone. Can be used with 
all operating systems Windows, macOS, iOS, Android. There is a student management tool. There are tools to help you prepare content and links and have communication tools There are tools to measure and evaluate grades, have AI and bot systems such as anti-piracy systems, making a quiz, and creating a survey.

Example of using Google Classroom at Faculty of Education, Mahachulalongkornrajavidyalaya University, Thailand which have been set for teaching and learning during COVID-19 situation.

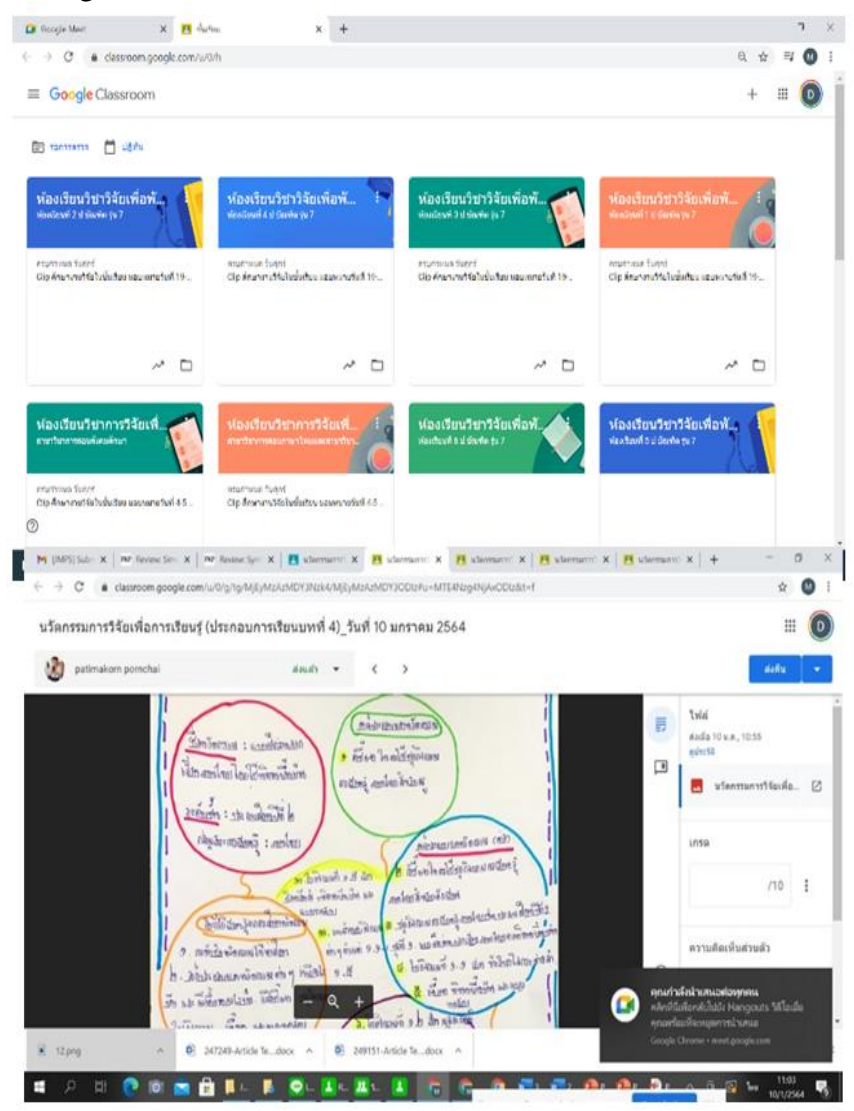

Fig.2 Online Classroom in Faculty of Education, MCU, Thailand

\section{Teach by YourSelf (Self Model)}

Teachers provide self-teaching through live teaching and conference tools such as Zoom, -OBS Studio, loom, Cisco Webex, and Skype. The highlight is that it can be used with all communication tools such as PC, Notebook, Tablet, Ipad, Smart Phone and can be used with all operating systems. The disadvantage is that there is no learning management tool for students. There are no tools to assist in providing content and links, and there are no tools to measure and evaluate grades.

\section{Virtual \& Mobile Studio (Techno Model)}

The highlight is that the teacher can prepare the content in both theory and practice, record high-definition videos of instruction, broadcast live via Youtube and Facebook, and support both theory and practice courses. (Both in the studio and in the LAB). The disadvantage is that there is no learning management tool for students. There are no tools to assist in providing content and links and no communication tools. There are no tools to measure and evaluate grades. (Department of Technology and Learning Innovation Office of Academic Resources Prince of Songkla University, 2020) [12].

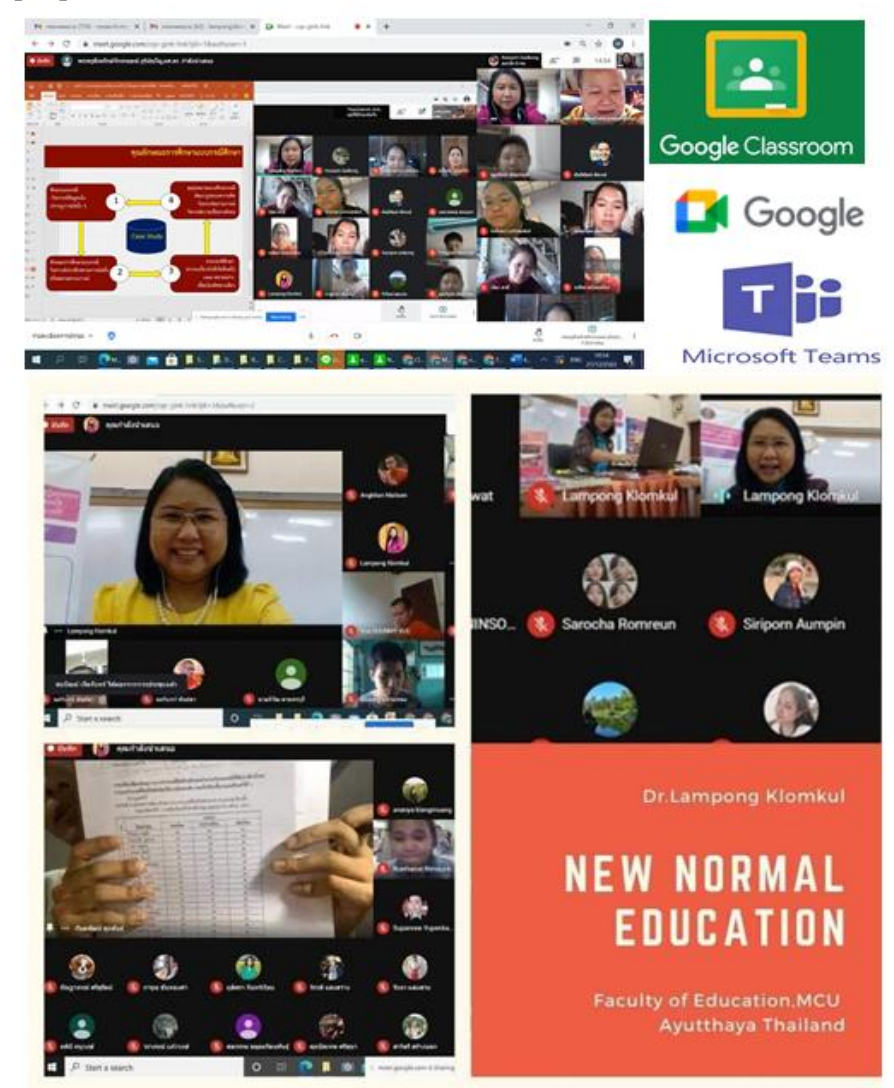

Fig. 3 Learning Activities through Online Platform

\section{Conclusion}

Thai online teaching and learning under the epidemic situation of Coronavirus disease 2019 (COVID-19) is therefore consistent with the current situation of the Thai study. It is also a good prevention of the spread of such viral disease and is also another measure to effectively control the disease. It is the study of the world context and apply them to the context of Thai society by 1) focusing on the curriculum adapted to the COVID-19 situation and communicate to all stakeholders of current Thai basic education curriculum, 2) Increase flexibility of structure, study time and diversity of learning styles. The flexibility to spend time and choice of study style allows teachers to design units that are appropriate and promote personalized learning, and 3) emphasis on accountability assessment should still be maintained, but should weigh the assessment of children's learning opportunities rather than measuring knowledge with exam scores. The current epidemic situation requires a variety of teaching and learning styles, so the quality of education that children receive in each area is not the same. Therefore, the same knowledge or skill score cannot be used to create liability. Otherwise, it may result in more inequality. The Ministry of Education should adjust the test-based criteria to weight the non-academic indicators (Non-academic measure) by collecting data on these metrics. Technology can help to reduce the burden of teachers, for example, use the Google Classroom system. 
This will help the districts to monitor and support the school more relevant to their needs.

\section{References}

[1] Office of the Education Council Secretariat, National Education Standards of 2018, Bangkok: Prik Wan Graphic Co., Ltd., 2018.

[2] W. Santipraphob. (2019). Preparation of "Thai people" for the modern world. Economic and Social Journal, Year 56, No. 2 July - December 2019, ISSN 02150892 NESDC. Bangkok: Office of the National Economic and Social Development Council.

[3] N. Nithisunthornwit, Science Development Technology and innovation to increase the competitiveness of Thailand. Economic and Social Journal Vol.57 No. 1 January June 2020 ISSN 0215-0892 NESDC. Bangkok: Office of the National Economic and Social Development Council, 2020.

[4] K. Jirawiriyawong. (2013). Souvenir from far away. Education Solution Amid the Wuhan Crisis. Thai Education Journal (OEC Journal) Year 17, No. 2 April - June 2020, Bangkok: Office of the Education Council Secretariat.

[5] K.J. Kim and C.J. Bonk, The Future of Online Teaching and Learning in Higher Education, 2006, Available: http://faculty.weber.edu/eamsel/Research $\%$ 20Groups/On line\% 20Learning / Bonk\% 20 (2006).pdf.

[6] I.E.Allen and J. Seaman, Learning on Demand: Online Education in the United States, 2009.Available: https://eric.ed.gov/?id=ED529931.

[7] D. Aaron, Adventure Learning: Transformative hybrid online education, 2007, Available: https://www. tandfonline.com/doi/abs/10.1080/0158791 0600789571.

[8] S.B. Eom, H. Joseph Wen and Nicholas Ashill. (2006) .The Determinants of Students' Perceived Learning Outcomes and Satisfaction in University Online Education: An Empirical Investigation.
Decision Sciences Journal of Innovative Education Volume 4 Number 2July 2006Printed in the U.S.A. Available: https://onlinelibrary.wiley.com/doi/epdf/10 .1111/ j.1540-4609.2006.00114.x.

[9] WORATHAN TECHNOLOGY,'COVID19' Education reform around the world! Using new technology for learning - 'Thai University' teaches online, 2020, Available: https://www.worathan.co.th/ details / 'COVID-19'_Und_ reform education around the world !

[10] Marketingoops. (2020). ' 'COVID-19' transforms education around the world! Using new technology to study - 'Thai University' taught online, March 15, 2020. / business-case / covid-19-reinvent-global-

education-system-with-educational-technology I.

[11] Technology and Learning Innovation Department Office of Academic Resources Prince of Songkla University, Technology and innovation to support teaching and learning among COVID-19, 2020, Available:

https://techno.oas.psu.ac.th/content/158 